\title{
Patterns of Breast Imaging Use Among Women with a Personal History of Breast Cancer
}

\author{
Louise M. Henderson, $P h D^{7}$, Laura Ichikawa, MS'2, Diana S. M. Buist, $P h D^{2}$, \\ Janie M. Lee, $M D^{3}$, Mary Bush, $M N^{2}$, Dianne Johnson, $B A^{2}$, Tracy Onega, $P h D^{4}$, \\ Larissa Nekhlyudov, $M D^{5}$, Karla Kerlikowske, $M D^{6,7}$, Diana L. Miglioretti, $P h D^{2,8}$, \\ Brian L. Sprague, $P h D^{9}$, and Karen J. Wernli, $P h D^{2}$
}

\begin{abstract}
'Department of Radiology, The University of North Carolina Chapel Hill NC, Chapel Hill, NC, USA; ${ }^{2}$ Kaiser Permanente Washington Health Research Institute, Seattle, WA, USA; ${ }^{3}$ Department of Radiology, Seattle Cancer Care Alliance, University of Washington, Seattle, WA, USA; ${ }^{4}$ Department of Biomedical Data Science, Geisel School of Medicine at Dartmouth, Lebanon, NH, USA; 5 Department of Medicine, Brigham and Women's Hospital, Boston, MA, USA; ${ }^{6}$ Department of Epidemiology and Biostatistics, University of California, San Francisco, San Francisco, CA, USA; ${ }^{7}$ Department of Medicine, University of California, San Francisco, San Francisco, CA, USA; ${ }^{8}$ Department of Public Health Sciences, School of Medicine, University of California, Davis, Davis, CA, USA; ${ }^{9}$ Department of Surgery, University of Vermont College of Medicine, Burlington, VT, USA.
\end{abstract}

BACKGROUND: National patterns of breast imaging in women with a personal history of breast cancer (PHBC) are unknown making evaluation of annual surveillance recommendations a challenge.

OBJECTIVE: To describe variation in use of mammography and breast magnetic resonance imaging (MRI) examinations beginning 6 months after diagnosis among women with PHBC in US community practice. We report on the breast imaging indication, imaging intervals, and time since breast cancer diagnosis by examination type.

DESIGN: Longitudinal study using cross-sectional data. SETTING: Breast Cancer Surveillance Consortium breast imaging facilities.

PARTICIPANTS: 19,955 women diagnosed between 2005 and 2012 with AJCC stage 0-III incident breast cancer who had 69,386 mammograms and 3,553 breast MRI examinations from January 2005 to September 2013; median follow-up of 37.6 months (interquartile range, 22.1-60.7).

MAIN MEASURES: Breast imaging indication, imaging intervals, and time since breast cancer diagnosis by examination type.

KEY RESULTS: Among women with a $\mathrm{PHBC}$ who received breast imaging, 89.4\% underwent mammography alone, $0.8 \%$ MRI alone, and $10.3 \%$ had both mammography and MRI. About half of mammograms and MRIs were indicated for surveillance vs. diagnostic, with an increase in the proportion of surveillance exams as time from diagnosis increased (mammograms, $45.7 \%$ at 1 year to $72.2 \%$ after 5 years; MRIs, $54.8 \%$ at 1 year to $78.6 \%$ after 5 years). In the first post-diagnosis period, $32.8 \%$ of women had $\geq 2$ breast imaging examinations and of these, $65.8 \%$ were less than 6 months apart. During the first 5-year postdiagnosis, the frequency of examinations per year

Electronic supplementary material The online version of this article (https://doi.org/10.1007/s11606-019-05181-6) contains supplementary material, which is available to authorized users.

Received August 14, 2018

Revised March 21, 2019

Accepted June 19, 2019

Published online August 13, 2019 decreased and the interval between examinations shifted towards annual examinations.

CONCLUSION: In women with a PHBC who received postdiagnosis imaging, a third underwent multiple breast imaging examinations per year during the first 2-year postdiagnosis despite recommendations for annual exams. As time since diagnosis increases, imaging indication shifts from diagnostic to surveillance.

KEY WORDS: breast cancer; cancer surveillance; mammography; breast magnetic resonance imaging; cancer survivorship.

J Gen Intern Med 34(10):2098-106

DOI: $10.1007 / \mathrm{s} 11606-019-05181-6$

(c) Society of General Internal Medicine 2019

\section{INTRODUCTION}

In 2016 in the US, there were an estimated 3.5 million women living with a personal history of breast cancer (PHBC); by 2026, this number is expected to increase to 4.5 million women. ${ }^{1}$ Guidelines from the American Cancer Society (ACS), the American Society of Clinical Oncology, and the National Comprehensive Cancer Network (NCCN) recommend annual surveillance mammography for women with a PHBC who have not received a bilateral mastectomy. ${ }^{2-5}$ However, surveillance mammography is imperfect; $35 \%$ of second breast cancers diagnosed in women with a PHBC occur within 1 year after a negative mammogram. ${ }^{6,7}$ Thus, women and providers may seek additional breast imaging options, either decreasing the interval between surveillance mammograms ${ }^{8}$ or looking to other modalities such as magnetic resonance imaging (MRI), despite few existing guidelines on supplemental modalities or evidence on the benefits and harms of frequent use. While the ACS and the NCCN support adjunct breast MRI screening for women with $>20 \%$ lifetime risk based on family history, a known cancer predisposition syndrome, or receipt of chest radiation therapy between ages 10 and 30 years, these organizations do not recommend annual 
MRI for surveillance of asymptomatic women with a PHBC irrespective of lifetime risk.

Surveillance mammography use in women with a PHBC ranges from 70 to $90 \%$ and has been reported to decrease by time since breast cancer diagnosis. ${ }^{9-15}$ Some women may undergo mammography for indications other than surveillance, based on facility specific protocols or reimbursement practices. Although breast MRI use has increased over the past 15 years, ${ }^{16,17}$ there is little information on MRI use among women with a PHBC. A few prior studies evaluated breast imaging examination types and/or frequency or intervals between examinations among women with a PHBC once they return to care after curative intent treatment, but these are limited to women with ductal carcinoma in situ (DCIS) or fail to capture the examination indication. ${ }^{9-15}$ From Breast Cancer Surveillance Consortium (BCSC) focus groups among women with PHBC, women reported multiple exams within the first few years post-treatment for breast cancer that decreased over time. ${ }^{18}$ Clinicians in key informant interviews also suggested that "their practice" includes diagnostic imaging and more frequent imaging, sometimes with breast MRI, for women with PHBC in the first 2-3 years post-diagnosis. ${ }^{19}$

Studies are needed to evaluate the comparative effectiveness of surveillance strategies in women with a PHBC; however, these studies will need to ensure the same type of examinations are being directly compared. For women with a PHBC, this may necessitate including all indications, not just surveillance mammograms, in order to appropriately estimate surveillance mammography use since exams performed for screening indications may currently be coded as diagnostic exams. We used BCSC data from 2005 to 2013 to describe the patterns of mammography and MRI use in women with a PHBC beginning 6 months after diagnosis. Specifically, we examined indication, frequency, and breast imaging intervals by time since breast cancer diagnosis to understand breast imaging patterns and guide future work focused on comparative studies of different imaging strategies and interventions aimed at promoting surveillance that is consistent with clinical guidelines.

\section{METHODS}

\section{Study Setting}

The BCSC is a collaboration of population-based breast imaging registries predominantly from community settings across the US. ${ }^{20,21} \mathrm{BCSC}$ registries obtain prospective risk factor data, which are linked to breast imaging data collected as part of routine clinical care. These data are linked with state cancer or Surveillance Epidemiology and End Results Program registries and pathology databases for incident and recurrent cancer outcome ascertainment. Each BCSC registry site and the Statistical Coordinating Center (SCC) received institutional review board approval for either active or passive consent or a waiver of consent to enroll participants, link data, and perform analyses. All procedures are Health Insurance Portability and Accountability Act compliant and all registries and the SCC received a Federal Certificate of Confidentiality and other protection for the identities of women, physicians, and facilities who are subjects of this research.

\section{Participants}

For this longitudinal study using cross-sectional data, we included data from five BCSC registries: the Carolina Mammography Registry, New Hampshire Mammography Network, San Francisco Mammography Registry, Kaiser Permanente Washington, and Vermont Breast Cancer Surveillance System. Women ages 18 and older diagnosed with American Joint Committee on Cancer (AJCC) ${ }^{22}$ stage 0-III primary breast cancer from 2005 to 2012 were included provided they did not receive a bilateral mastectomy as part of initial treatment. Women were also required to have at least one breast imaging examination during the follow-up period to be included.

\section{Measures}

Women self-report their race, ethnicity, menopausal status, and education at each examination. Community-level income was ascertained using the woman's zip code linked with 2010 US Census data. We calculated 5-year and lifetime breast cancer risk at the time of diagnosis. The National Cancer Institute Breast Cancer Risk Assessment Tool (BRCAT) was used to calculate lifetime breast cancer risk ${ }^{23-28}$ and the BCSC risk model version 1 was used to estimate 5 -year breast cancer risk. ${ }^{29,30}$ Information at the time of the incident breast cancer included diagnosis date, type of primary therapy (breast conserving surgery without radiation therapy (RT), breast conserving surgery with RT, and mastectomy), AJCC stage, tumor size, ER status, and progesterone receptor (PR) status.

Mammography and breast MRI examinations were included if they occurred at least 6 months after primary breast cancer diagnosis and were performed at BCSC facilities between July 2005 and September 2013. Examination indication and date were obtained primarily using electronic radiology systems but also included chart abstraction, scanned forms, and billing systems. Indication was reported by the facility and included (1) surveillance for a second primary or recurrent breast cancer; (2) additional evaluation; (3) short-interval follow-up; (4) evaluation of a breast problem; (5) evaluation of extent of disease or axillary adenopathy, unknown primary (MRI only); and (6) diagnostic not otherwise specified (NOS). We excluded mammograms with "other indications" and MRI exams with an indication for response to chemotherapy or implant evaluation. We included all imaging examinations, regardless of self-reported symptoms.

We categorized the time since diagnosis as 1 year ( 6 to less than 18 months), 2 years (18 to less than 30 months), 3 years ( 30 to less than 42 months), 4 years ( 42 to less than 54 months), 5 years (54 to less than 66 months), and $>5$ years $(66+$ 
months) and evaluated examination frequency in each category. We also evaluated the interval between examinations based on months since a prior breast imaging examination using the most recent of self-reported and prior examination date in the BCSC database.

\section{Statistical Analysis}

During the follow-up period, women could have multiple breast imaging examinations. We calculated follow-up time as the time from breast cancer diagnosis until last recorded imaging examination. We calculated frequencies of imaging examination indication by modality type (mammography or MRI) and time since breast cancer diagnosis. We compared patterns of indication by stage of breast cancer diagnosis and by primary therapy (breast conserving surgery without radiation therapy (RT), breast conserving surgery with RT, and unilateral mastectomy) to evaluate if patterns differed by either of these factors. We also examined the number of examinations per woman and months since prior examination by year since diagnosis overall and separately for mammograms and MRI.

\section{RESULTS}

\section{Cohort Characteristics}

We included 19,955 women with a PHBC who received at least one breast imaging exam post-diagnosis (Table 1).

\section{Breast Imaging}

During follow-up, 19,955 women with a PHBC underwent 69,386 mammograms and 3,553 breast MRIs; median followup was 37.6 months (interquartile range, 22.1 to 60.7 ). Most women had mammography alone (89.4\%) (Table 2). Among women who underwent breast MRI, most had a combination of MRI and mammography, with $<1 \%$ having breast MRI alone.

\section{Patterns of Imaging by Indication and Time Since Diagnosis}

Examination indication varied by imaging modality and time since diagnosis (Table 3). In the first post-diagnosis period, $45.7 \%$ of mammograms were surveillance, which increased to $72.2 \%$ at $>5$-year post-diagnosis ( $66+$ months). Additionally, short-interval follow-up mammograms declined from $23.7 \%$ at 1 -year post to $3.3 \%$ at $>5$ years post, as did additional evaluation mammograms $(7.4 \%$ at 1 year versus $3.6 \%$ at $>$ 5 years). Evaluation of a breast problem remained fairly constant over the follow-up time, ranging from 16.9 to $19.2 \%$.

For MRI examinations, indication also varied by time since diagnosis. Similar to patterns observed for mammography, the proportion of MRIs coded as surveillance increased as time since diagnosis increased; $54.8 \%$ at 1 year to $78.6 \%$ at >
5 years. As surveillance MRIs increased by time since diagnosis, short-interval follow-up (18.5\% at 1 year versus $4.8 \%$ at $>5$ years), additional evaluation $(9.9 \%$ at 1 year versus $4.1 \%$ at $>5$ years), and extent of disease/axillary adenopathy decreased over time (10.6\% at 1 year versus $3.0 \%$ at $>5$ years).

Indication by time since diagnosis stratified by AJCC stage did not show differences in imaging patterns (Online Appendix 1 in the Electronic Supplementary Material (ESM)). Women with breast conserving surgery with or without RT had similar patterns to the overall results (Online Appendix 2 in the ESM). Women with mastectomy who underwent unilateral mammography had a higher proportion of examinations coded as surveillance in the first few years and a lower proportion of mammograms coded as short-interval follow-up.

Comparing patterns for mammography and MRI in women with a PHBC who received at least one breast imaging exam post-diagnosis, the proportion of examinations with an indication of surveillance was consistently lower for mammograms than for MRIs (Table 3). Patterns for other indications were similar for mammography and MRI.

In the first-year post-diagnosis, $81.8 \%$ of women had at least one breast imaging examination and one-third had more than one examination; this decreased over time such that only $13 \%$ of women had more than one examination at 5 years post-diagnosis (Table 4). The pattern for mammography is similar to the overall pattern as the majority of examinations are mammograms. However, only $6 \%$ of women with an MRI had multiple MRI examinations in the first-year post-diagnosis. In the first-year post-diagnosis, women who underwent mammography had multiple examinations at fairly short intervals (18.5\% within 3 months of a prior examination, $45.0 \%$ within 3 to $<6$ months, $35.1 \%$ within 6 to $<9$ months, and $1.4 \%$ within 9 to $<12$ months) (Fig. 1a). As years postdiagnosis increased, the pattern shifted so that by years $3-5$, most women shifted to 12 to $<24$ months between examinations.

The pattern for women undergoing MRI differed from that of mammography (Fig. 1b). In women who had MRI in the first-year post-diagnosis, $55.2 \%$ had a prior imaging examination within 3 months, $31.3 \%$ in 3 to < 6 months, $13.1 \%$ in 6 to $<9$ months, and $0.5 \%$ in 9 to $<12$ months. While the proportion of women having examinations within $<3$ months decreased over time, the majority of women with MRIs had mammography at intervals shorter than every 12 months.

\section{DISCUSSION}

Our findings provide descriptive information about breast imaging examinations that women with a PHBC and at least one breast imaging exam post-diagnosis receive during the post-treatment phase of care. We found that in the 6 to 18 months post-diagnosis, about $82 \%$ of women have at least one breast imaging examination and of those with an 
Table 1 Sociodemographic and Tumor Characteristics of 19,955

Women with a Personal History of Breast Cancer (PHBC), Breast Cancer Surveillance Consortium (BCSC) 2005-2013

\begin{tabular}{|c|c|}
\hline Characteristic & $\begin{array}{l}\text { Women with } \\
\text { PHBC } \\
N(\%) \\
N=19,955\end{array}$ \\
\hline \multicolumn{2}{|l|}{ Age group, years } \\
\hline $18-39$ & $781(4)$ \\
\hline $40-49$ & $3670(18)$ \\
\hline $50-59$ & 5449 (27) \\
\hline $60-69$ & $5385(27)$ \\
\hline $70-79$ & $3220(16)$ \\
\hline$\geq 80$ & $1450(7)$ \\
\hline \multicolumn{2}{|l|}{ Race } \\
\hline White & $14376(72)$ \\
\hline African-American & $1702(9)$ \\
\hline Asian or Pacific Islander & $2534(13)$ \\
\hline Other & $498(3)$ \\
\hline Hispanic & $790(4)$ \\
\hline Missing & 55 \\
\hline \multicolumn{2}{|l|}{ Menopausal status } \\
\hline Post-menopausal & 11107 (76) \\
\hline Pre/Peri menopausal & $3421(24)$ \\
\hline Missing & 5427 \\
\hline \multicolumn{2}{|l|}{ BI-RADS breast density at time of diagnosis } \\
\hline Almost entirely fat & $773(7)$ \\
\hline Scattered fibroglandular tissue & $4929(42)$ \\
\hline Heterogenously dense & 4969 (43) \\
\hline Extremely dense & $963(8)$ \\
\hline Missing & 8321 \\
\hline \multicolumn{2}{|l|}{ Education } \\
\hline$<$ High school graduate & $904(7)$ \\
\hline High school graduate/GED & $2657(21)$ \\
\hline Some college & $3340(27)$ \\
\hline College graduate & $5687(45)$ \\
\hline Missing & 7367 \\
\hline \multicolumn{2}{|l|}{ Income (approx. quartiles) } \\
\hline$<\$ 47,000$ & $4185(21)$ \\
\hline$\$ 47,000<\$ 63,000$ & $4628(23)$ \\
\hline$\$ 63,000<<86,000$ & $5312(27)$ \\
\hline$\geq \$ 86,000$ & $5719(29)$ \\
\hline Missing & 111 \\
\hline \multicolumn{2}{|l|}{ BRCAT lifetime risk* } \\
\hline$<15 \%$ & $13798(93)$ \\
\hline 15 to $<20 \%$ & $717(5)$ \\
\hline$\geq 20 \%$ & $328(2)$ \\
\hline Missing & 5112 \\
\hline \multicolumn{2}{|l|}{ BCSC 5-year risk* } \\
\hline$<1.67 \%$ & $5252(59)$ \\
\hline 1.67 to $<3 \%$ & $2776(31)$ \\
\hline$\geq 3 \%$ & $847(10)$ \\
\hline Missing & 11080 \\
\hline \multicolumn{2}{|l|}{ AJCC stage } \\
\hline 0 & $4502(23)$ \\
\hline I & $8620(43)$ \\
\hline IIA & $3505(18)$ \\
\hline IIB & $1822(9)$ \\
\hline III & $1506(8)$ \\
\hline \multicolumn{2}{|l|}{ Tumor size } \\
\hline$<10 \mathrm{~mm}$ & $5014(26)$ \\
\hline 10 to $<20 \mathrm{~mm}$ & $6685(35)$ \\
\hline 20 to $<50 \mathrm{~mm}$ & $5711(30)$ \\
\hline$\geq 50 \mathrm{~mm}$ & $1608(8)$ \\
\hline Missing & 937 \\
\hline \multicolumn{2}{|l|}{ Estrogen receptor status } \\
\hline Negative & $3250(18)$ \\
\hline Positive & $15276(82)$ \\
\hline Missing & 1429 \\
\hline \multicolumn{2}{|l|}{ Progesterone receptor status } \\
\hline Negative & $5045(27)$ \\
\hline Positive & $13470(73)$ \\
\hline Missing & 1440 \\
\hline \multicolumn{2}{|l|}{ Surgery at time of incident breast cancer } \\
\hline None & $427(2)$ \\
\hline Breast conserving surgery without RT & 3339 (17) \\
\hline
\end{tabular}

(continued on next page)
Table 1. (continued)

\begin{tabular}{ll}
\hline \hline Characteristic & $\begin{array}{l}\text { Women with } \\
\text { PHBC } \\
\boldsymbol{N}(\mathbf{\%}) \\
\mathbf{N = 1 9 , 9 5 5}\end{array}$ \\
& $10834(56)$ \\
& $4844(25)$ \\
Breast conserving surgery with RT & \\
$\begin{array}{l}\text { Mastectomy (unilateral or laterality } \\
\text { unspecified) }\end{array}$ & 511 \\
Missing & \\
Year of diagnosis & $2795(14)$ \\
2005 & $3001(15)$ \\
2006 & $2955(15)$ \\
2007 & $2931(15)$ \\
2008 & $2602(13)$ \\
2009 & $2165(11)$ \\
2010 & $2087(10)$ \\
2011 & $1419(7)$ \\
2012 &
\end{tabular}

BCRAT Breast Cancer Risk Assessment Tool, BI-RADS Breast Imaging Reporting and Data System, AJCC American Joint Committee on Cancer, $R T$ radiation therapy

*BRCAT and BCSC risk scores are calculated at the mammogram prior to breast cancer diagnosis

examination, about one-third had more than one examination in the first year. Multiple breast imaging examinations per year (mostly mammograms) were common and continued for the first few years post-diagnosis, suggesting there is a subset of women with a PHBC who are undergoing breast imaging more frequently than recommended guidelines. As time since diagnosis increased, the proportion of examinations (both mammography and MRI) with an indication of surveillance increased. We did not observe widespread use of MRI, either alone or in conjunction with mammography for women with a PHBC. When MRI was used, it tended to occur within 3 or 6 months of mammography.

Our study provides observational data to supplement prior reports of breast imaging in women with a PHBC based on survey and claims data. Ruddy et al. used claims data from 27,212 women with PHBC and found that in the first-year after definitive breast cancer surgery $78 \%$ of women had mammography alone, $1 \%$ had MRI alone, $8 \%$ had both mammography and MRI, and $13 \%$ had neither. ${ }^{13}$ This is similar to our study in which $82 \%$ of women had breast imaging in the first year, with most having mammography alone $(76 \%)$, followed by mammography and MRI $(4 \%)$ and $<1 \%$ having MRI alone. Given that Ruddy et al. used claims data, they were unable to determine the indication for the examinations. Another study of women with a personal history of DCIS found that during the first year of follow-up, $79 \%$ of women had at least one surveillance mammogram and $11.5 \%$ had more than one. ${ }^{14}$ In the second year, $75 \%$ had at least one surveillance mammogram but only $4.6 \%$ had more than one surveillance mammogram. In the first-year of follow-up, 5.3\% of women had at least one diagnostic mammogram, with a slight increase in year 2 to $11.3 \% .{ }^{15}$ Examination indications in our study and these two DCIS studies differ, as a much lower proportion of mammograms had a surveillance 
Table 2 Breast Imaging Combinations Among 19,955 Women with a Personal History of Breast Cancer, Breast Cancer Surveillance Consortium 2005-2013

\begin{tabular}{ll}
\hline \hline Imaging modality & $\boldsymbol{N}$ women $(\boldsymbol{\%}) * \mathbf{N = 1 9 , 9 5 5}$ \\
\hline Mammogram only & $17,836(89.4)$ \\
MRI only & $162(0.8)$ \\
Any MRI and mammogram & $1,957(9.8)$ \\
1 MRI and 1 mammogram & $216(1.1)$ \\
1 MRI and > 1 mammogram & $953(4.8)$ \\
$>1$ MRI and $\geq 1$ mammogram & $788(4.0)$ \\
\hline
\end{tabular}

*Women in this table have differing follow-up (median= 37.6 months, $I Q R=22.1$ to 60.7$)$

indication in our study. The pattern of multiple surveillance mammograms in the 1-year post-diagnosis is similar to our findings; however, we did not observe such a sharp decline in the proportion of women with multiple mammograms in year 2. These differences could be due to differing stage distributions in studies, indication for exam, or availability and use of other imaging modalities such as MRI. Differences in the proportion of women with more than one exam between studies could stem from the indications included.

Breast MRI in the general population is increasing $^{20,21}$ with limited information on its use and effectiveness in women with a PHBC. Using BCSC data from 2005 to 2009, Wernli and colleagues reported an increase in breast MRI use from 4.2 to 11.5 examinations per 1000 women from 2005 to 2009 with $45 \%$ of MRIs performed in women with a PHBC. ${ }^{16}$ Stout et al. reported an increase in MRI use (6.5 to 130.7 examinations per 10,000 women) in a northeastern US population from 2000 to 2009 using claims data, ${ }^{17}$ with $23 \%$ of MRIs performed in women with a PHBC. Stout et al. used an algorithm to define examination indication and among 3167 women with a PHBC with at least one MRI, a similar proportion had MRI for staging/ treatment and surveillance $(66.7 \%$ versus $65.9 \%$, respectively) while a lower proportion (34.0\%) had MRI for diagnostic evaluation. $65.9 \%$ of women in the Stout study who had surveillance MRI is similar to the proportion of women in our study with surveillance indication $(54.8 \%$ in year 1 to $78.6 \%$ at $>5$ years).

This study provides important information for understanding the type of imaging women with a PHBC are undergoing. Through the course of 6 focus groups from 41 women with a PHBC in three BCSC geographic regions of the US in 2014, almost all women reported receiving mammography every 3 to 6 months for 1 to 3 years after completion of treatment, and then annual mammography or staggered mammography and MRI every 6 months. ${ }^{18}$ The women reported that they did not question having multiple examinations in a given year; in fact, women stated that they were assured that their provider was looking for another cancer. These focus group findings of multiple examinations in the first few years are similar to our findings from almost 20,000 women.

In 2018, findings from a national 8-question online survey of radiologists regarding their use of diagnostic versus screening mammography for women with a PHBC found significant variability in imaging protocols for women with a PHBC based on women's treatment (lumpectomy versus mastectomy) and facility characteristics. ${ }^{31}$ Radiologists reported that protocols for women with lumpectomy were more likely to have a combination of diagnostic and screening examinations compared

Table 3 Indication of Breast Imaging Examination by Modality and Time Since Breast Cancer Diagnosis, Breast Cancer Surveillance Consortium 2005-2013

\begin{tabular}{|c|c|c|c|c|c|c|}
\hline \multirow[t]{2}{*}{ Modality and indication } & \multicolumn{6}{|c|}{$N(\%)$ examinations in the time since diagnosis (months) } \\
\hline & \multirow{2}{*}{$\begin{array}{l}\text { 1-year } \\
\text { post- } \\
\text { diagnosis } \\
(6 \text { to }<18 \text { mo }) \\
N(\%)\end{array}$} & \multirow{2}{*}{$\begin{array}{l}\text { 2-year } \\
\text { post-diagnosis } \\
(18 \text { to }<30 \text { mo) } \\
N(\%)\end{array}$} & \multirow{2}{*}{$\begin{array}{l}\text { 3-year } \\
\text { post-diagnosis } \\
(30 \text { to }<42 \text { mo) } \\
N(\%)\end{array}$} & \multirow{2}{*}{$\begin{array}{l}\text { 4-year } \\
\text { post-diagnosis } \\
(42 \text { to }<54 \text { mo }) \\
N(\%)\end{array}$} & \multirow{2}{*}{$\begin{array}{l}\text { 5-year } \\
\text { post-diagnosis } \\
(54 \text { to }<66 \text { mo) } \\
N(\%)\end{array}$} & \multirow{2}{*}{$\begin{array}{l}>5 \text {-year } \\
\text { post- } \\
\text { diagnosis } \\
(66+\text { mo) } \\
N(\%)\end{array}$} \\
\hline & & & & & & \\
\hline $\begin{array}{l}\text { Mammography } \\
\text { indication }(N=69,386)\end{array}$ & $N=21,331$ & $N=15,693$ & $N=11,585$ & $N=8,477$ & $N=5,894$ & $N=6,406$ \\
\hline Surveillance & $9,742(45.7)$ & $8,548(54.5)$ & $6,846(59.1)$ & $5,195(61.3)$ & $3711(63.0)$ & $4,625(72.2)$ \\
\hline Additional evaluation & $1570(7.4)$ & $1302(8.3)$ & $908(7.8)$ & $562(6.6)$ & $372(6.3)$ & $230(3.6)$ \\
\hline Short-interval follow-up & $5,049(23.7)$ & $2533(16.1)$ & $1,487(12.8)$ & $1,032(12.2)$ & $557(9.5)$ & $214(3.3)$ \\
\hline Evaluation of breast problem & $3,786(17.8)$ & $2,682(17.1)$ & $1,961(16.9)$ & $1,454(17.2)$ & $1,113(18.9)$ & $1,227(19.2)$ \\
\hline Diagnostic, not otherwise specified & $1,184(5.6)$ & $628(4.0)$ & $383(3.3)$ & $234(2.8)$ & $141(2.4)$ & $110(1.7)$ \\
\hline MRI indication $(N=3,553)$ & $N=1,141$ & $N=807$ & $N=599$ & $N=434$ & $N=301$ & $N=271$ \\
\hline Surveillance & $625(54.8)$ & $539(66.8)$ & $440(73.5)$ & $314(72.4)$ & $230(76.4)$ & $213(78.6)$ \\
\hline Additional evaluation & $113(9.9)$ & $87(10.8)$ & $44(7.4)$ & $33(7.6)$ & $20(6.6)$ & $11(4.1)$ \\
\hline Short-interval follow-up & $211(18.5)$ & $78(9.7)$ & $58(9.7)$ & $44(10.2)$ & $19(6.3)$ & $13(4.8)$ \\
\hline Evaluation of breast problem & $71(6.2)$ & $65(8.1)$ & $41(6.8)$ & $30(6.9)$ & $25(8.3)$ & $26(9.6)$ \\
\hline $\begin{array}{l}\text { Extent of disease/axillary adenop- } \\
\text { athy }\end{array}$ & $121(10.6)$ & $38(4.7)$ & $16(2.7)$ & $13(3.0)$ & $7(2.3)$ & $8(3.0)$ \\
\hline
\end{tabular}

MRI magnetic resonance imaging, mo month 
Table 4 Number of Examinations by Time Since Breast Cancer Diagnosis, Overall and by Exam Modality for All Indications, Breast Cancer Surveillance Consortium 2005-2013

\begin{tabular}{|c|c|c|c|c|c|c|}
\hline & \multicolumn{6}{|c|}{ Number of years post-diagnosis (months) } \\
\hline & \multirow{2}{*}{$\begin{array}{l}\text { 1-year } \\
\text { post-diagnosis } \\
(6 \text { to }<18 \mathrm{mo}) \\
N(\%)\end{array}$} & \multirow{2}{*}{$\begin{array}{l}\begin{array}{l}2 \text {-year } \\
\text { post-diagnosis } \\
(18 \text { to }<30 \mathrm{mo})\end{array} \\
N(\%)\end{array}$} & \multirow{2}{*}{$\begin{array}{l}\text { 3-year } \\
\text { post-diagnosis } \\
(30 \text { to }<42 \text { mo) }\end{array}$} & \multirow{2}{*}{$\begin{array}{l}\begin{array}{l}\text { 4-year } \\
\text { post-diagnosis } \\
(42 \text { to }<54 \mathrm{mo})\end{array} \\
N(\%)\end{array}$} & \multirow{2}{*}{$\begin{array}{l}\text { 5-year } \\
\text { post-diagnosis } \\
(54 \text { to }<66 \text { mo) }\end{array}$} & \multirow{2}{*}{$\begin{array}{l}>5 \text {-year } \\
\text { post-diagnosis } \\
(66+\text { mo) }\end{array}$} \\
\hline & & & & & & \\
\hline \multicolumn{7}{|l|}{ All exams } \\
\hline$N$ women & 16,318 & 13,139 & 10,265 & 7,667 & 5,438 & 3,979 \\
\hline$N$ exams & 22,472 & 16,500 & 12,184 & 8,911 & 6,195 & 6,677 \\
\hline \multicolumn{7}{|c|}{$N$ exams per woman } \\
\hline 1 & $10,965(67.2)$ & $10,109(76.9)$ & $8,512(82.9)$ & $6,521(85.1)$ & $4,735(87.1)$ & $2,123(53.4)$ \\
\hline 2 & $4,625(28.3)$ & $2,720(20.7)$ & $1,601(15.6)$ & $1,056(13.8)$ & $653(12.0)$ & $1,206(30.3)$ \\
\hline 3 or more & $728(4.5)$ & $310(2.4)$ & $152(1.5)$ & $90(1.2)$ & $50(0.9)$ & $650(16.3)$ \\
\hline \multicolumn{7}{|c|}{ Mammogram } \\
\hline$N$ women & 16,065 & 12,962 & 10,134 & 7,579 & 5,356 & 3,948 \\
\hline $\mathrm{N}$ exams & 21,331 & 15,693 & 11,585 & 8,477 & 5,894 & 6,406 \\
\hline \multicolumn{7}{|c|}{$N$ exams per woman } \\
\hline 1 & $11,305(70.4)$ & $10,423(80.4)$ & $8,774(86.6)$ & $6,733(88.8)$ & $4,841(90.4)$ & $2,171(55.0)$ \\
\hline 2 & $4,282(26.7)$ & $2,356(18.2)$ & $1,275(12.6)$ & $795(10.5)$ & $494(9.2)$ & $1,200(30.4)$ \\
\hline 3 or more & $478(3.0)$ & $183(1.4)$ & $85(0.8)$ & $51(0.7)$ & $21(0.4)$ & $577(14.6)$ \\
\hline \multicolumn{7}{|l|}{ MRI } \\
\hline$N$ women & 1,075 & 780 & 579 & 422 & 293 & 211 \\
\hline$N$ exams & 1,141 & 807 & 599 & 434 & 301 & 271 \\
\hline \multicolumn{7}{|c|}{$N$ exams per woman } \\
\hline 1 & $1,010(94.0)$ & $753(96.5)$ & $559(96.5)$ & $411(97.4)$ & $285(97.3)$ & $159(75.4)$ \\
\hline 2 & $64(6.0)$ & $27(3.5)$ & $20(3.5)$ & $10(2.4)$ & $8(2.7)$ & $45(21.3)$ \\
\hline 3 or more & $1(0.1)$ & $0(0)$ & $0(0)$ & $1(0.2)$ & $0(0)$ & $7(3.3)$ \\
\hline
\end{tabular}

MRI magnetic resonance imaging, mo month

to women with mastectomy, who were more likely to have diagnostic only or screening only examinations. The most frequently reported imaging interval was every 6 months for 1-2 years (49\%), with the next most common interval every 12 months for 2-5 years then screening (33\%), and the least common interval was for 6 months-1 year then screening (18\%). Radiologists working in academic settings were less likely to recommend diagnostic mammography after lumpectomy or mastectomy than community radiologists and were less likely to use diagnostic surveillance for periods beyond 2 years. In our results stratified by treatment type (Online Appendix 2 in the ESM), we found that women with a PHBC treated with mastectomy had a consistently higher proportion of examinations coded as surveillance by time since diagnosis.

Breast imaging examination indication in BCSC data is assigned at the breast imaging facility with variability in how this information is documented. Indication may come from the interpreting radiologist, the technologist performing the examination, the scheduler, or the physician who referred the woman for the examination. Medicare will pay for an annual screening or diagnostic mammogram for women with a $\mathrm{PHBC}^{32}$ and the ACR Practice Parameter of Screening and Diagnostic Mammography states that asymptomatic women with a PHBC may undergo screening or diagnostic mammography at the discretion of the facility, ${ }^{33}$ which may drive some of the observed variability in patterns for indication. Due to differences in underlying disease prevalence by indication, analyses of performance and outcomes are typically stratified by indication. Our observational data from community practice suggest a significant proportion of examinations are coded as diagnostic when they may be performed for surveillance. Using 2007-2013 BCSC data from 2,084,052 digital screening and diagnostic mammograms in women ages 18 and older, $5.3 \%$ of exams had an indication of evaluation of a breast problem, ${ }^{34,35}$ which is much lower than the 16.9-19.2\% we found in women with a PHBC.

A major strength of our study is the BCSC data which is the only national data source that collects breast imaging data with the level of detail needed to evaluate patterns and frequency of imaging indication. While women could receive imaging outside of BCSC registry catchment areas, in a subset of 31,628 examinations with a prior mammogram date from both selfreport and the BCSC database, 97\% have the two dates within 1 year of each other. We are unable to make this comparison for MRI as date of prior MRI is not available in the BCSC data. Additionally, we do not have complete 5-year follow-up for all women.

Our study showed that while women with a PHBC are recommended to undergo annual surveillance mammography, a third of women with a PHBC and at least one breast imaging exam receive multiple breast imaging examinations per year during the first 2 years post-diagnosis. Heterogeneity in breast imaging indication by time since breast cancer diagnosis may well be a reflection of reimbursement and facility variation. The patterns of more surveillance examinations as the time since diagnosis 


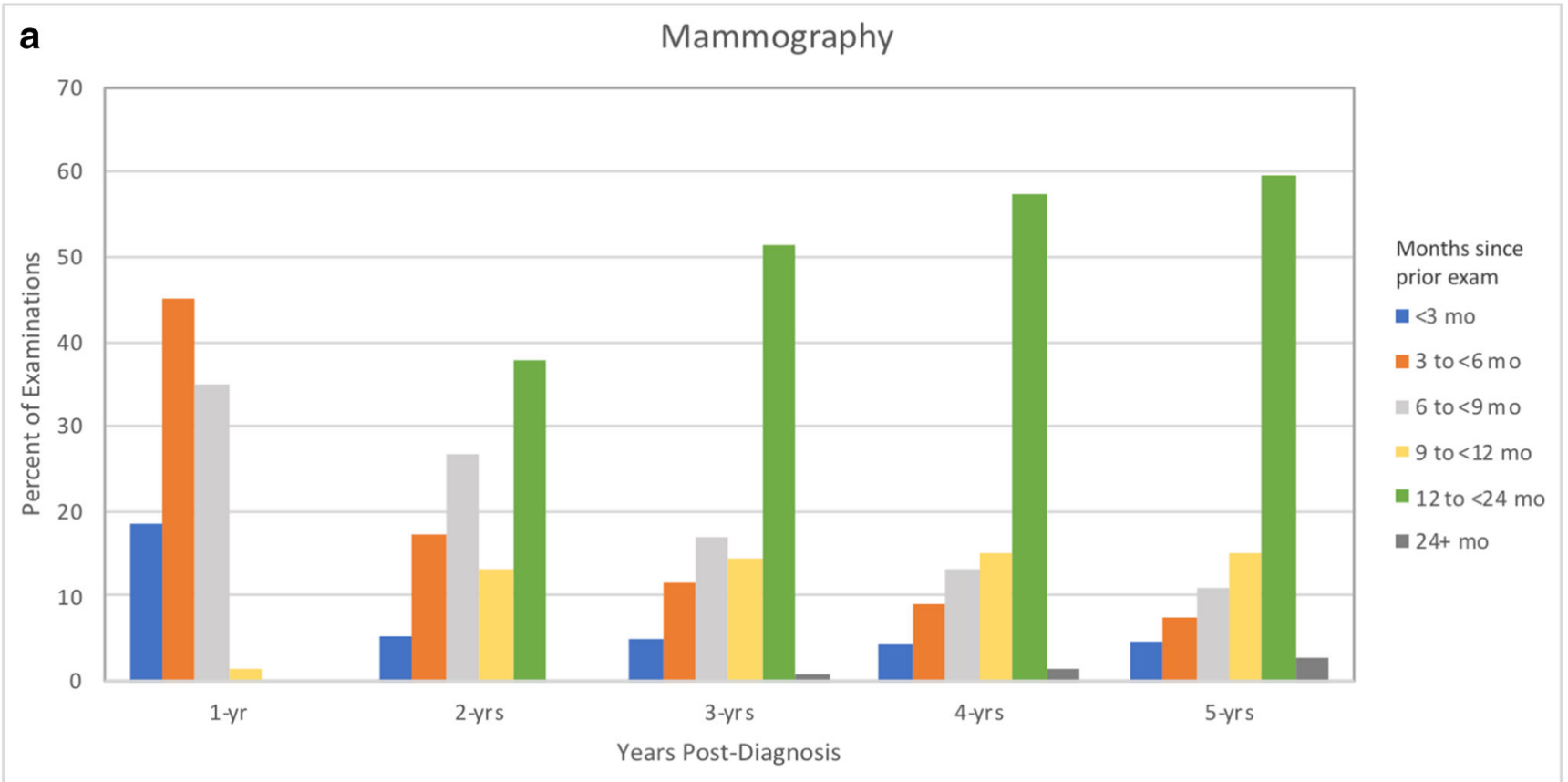

b

MRI

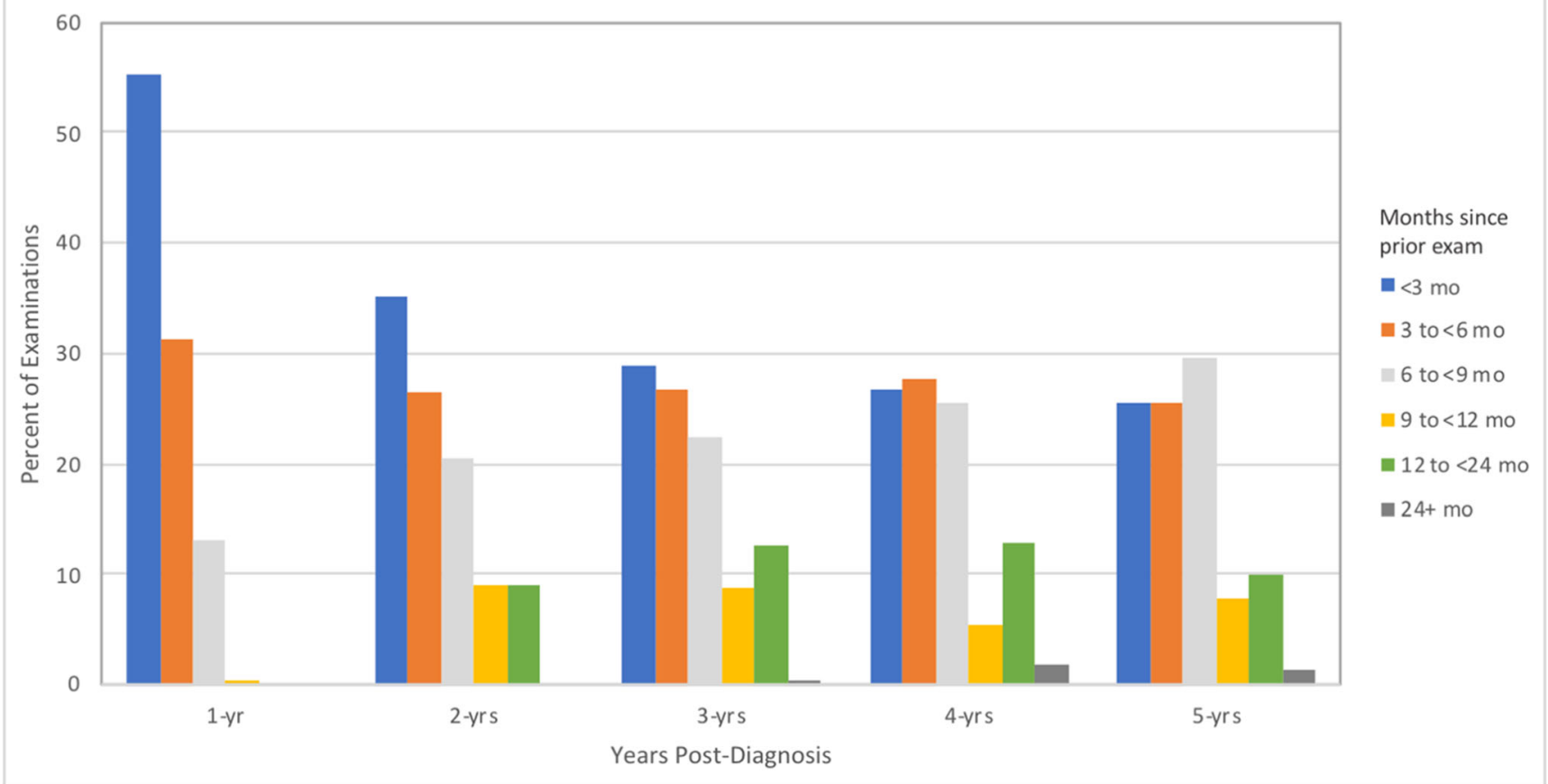

Fig. 1 Observed frequency of mammography (panel a) and MRI (panel b) examinations by the number of years post-diagnosis and months since prior examination in women with a personal history of breast cancer. Blue bars represent exams with another exam in the prior 3 months, orange bars represent exams with another exam in the prior 3 to less than 6 months, light gray bars represent exams with another exam in the prior 6 to less than 9 months, yellow bars represent exams with another exam in the prior 9 to less than 12 months, green bars represent exams with another exam in the prior 12 to less than 24 months, and dark gray bars represent exams with another exam in more than 24 months. a Proportion of mammograms by months since prior examination and time since breast cancer diagnosis, Breast Cancer Surveillance Consortium 2005-2013. b Proportion of MRI examinations by months since prior examination and time since breast cancer diagnosis, Breast Cancer Surveillance Consortium 2005-2013.

increases and the use of multiple examinations in the first few years appears to be in line with women's self-reports as well as those of radiologists. Comparative effectiveness studies are needed to evaluate different surveillance strategies in women with a PHBC and to assess potential overutilization of imaging. To conduct these studies, 
additional work is needed to understand what is driving facility variability in coding indication such as time since diagnosis, calendar year, and patient characteristics.

Acknowledgments: We thank the participating women, mammography facilities, and radiologists for the data they have provided for this study. Further, we thank the study Patient Advisory Board and Stakeholder Panel for their ongoing support of this research project.

Corresponding Author: Louise M. Henderson, $\mathrm{PhD}$; Department of Radiology The University of North Carolina Chapel Hill NC, Chapel Hill, NC 27599-7515, USA (e-mail: Louise_Henderson@med.unc.edu).

Authors' Contribution The collection of cancer and vital status data used in this study was supported in part by several state public health departments and cancer registries throughout the US. For a full description of the BCSC, please see: http://www.bcsc-research.org/.

Funding This study was funded by the Patient-Centered Outcomes Research Institute (PCORI) (grant number CE-1304-6656 "Comparative effectiveness of surveillance imaging modalities in breast cancer survivors") and the National Cancer Institute (grant numbers: PO1 CA154292, U54 CA163303).

\section{Compliance with Ethical Standards}

Conflict of Interest: Author Diana L. Miglioretti was a member of the Scientific Advisory Board for Hologic in 2017. Author Janie M. Lee is a consultant for General Electric Healthcare and receives a Research Grant from General Electric Healthcare. All remaining authors declare that they do not have a conflict of interest.

Disclaimer: The design and conduct of the study; collection, management, analysis, and interpretation of the data; preparation, review, or approval of the manuscript; and decision to submit the manuscript for publication are solely the responsibility of the authors and does not necessarily represent the official views of the Patient-Centered Outcomes Research Institute, the National Cancer Institute or the National Institutes of Health

Publisher's Note: Springer Nature remains neutral with regard to jurisdictional claims in published maps and institutional affiliations.

\section{REFERENCES}

1. Miller KD, Siegel RL, Lin CC, et al. Cancer Treatment and Survivorship Statistics, 2016. CA Cancer J Clin 2016;66:271-289.

2. Runowicz CD, Leach CR, Henry NL, Henry KS, Mackey HT, CowensAlvarado RL, Cannady RS, Pratt-Chapman ML, Edge SB, Jacobs LA Hurria A, Marks LB, LaMonte SJ, Warner E, Lyman GH, Ganz PA. American Cancer Society/American Society of Clinical Oncology Breast Cancer Survivorship Care Guideline. J Clin Oncol. 2016;34(6):611-35.

3. Khatcheressian JL, Hurley P, Bantug E, Esserman LJ, Grunfeld E, Halberg F, Hantel A, Henry NL, Muss HB, Smith TJ, Vogel VG, Wolff AC, Somerfield MR, Davidson NE, American Society of Clinical Oncology. Breast cancer follow-up and management after primary treatment: American Society of Clinical Oncology clinical practice guideline update. J Clin Oncol. 2013;31:961-5.

4. National Comprehensive Cancer Network (NCCN). Clinical Practice Guidelines in Oncology - Breast Cancer. Fort Washington, PA: National Comprehensive Cancer Network (NCCN); 2016 [cited 2016 January 6]; Clinical Practice Guidelines in Oncology - Breast Cancer, Version 1.2016. Available from: http://nccn.org. Accessed 05/07/2019.

5. Lee CH. Dershaw DD, Kopans D, Evans P, Monsees B, Monticciolo D Brenner RJ, Bassett L, Berg W, Feig S, Hendrick E, Mendelson E, D'Orsi C, Sickles E, Burhenne LW. Breast cancer screening with imaging: recommendations from the Society of Breast Imaging and the ACR on the use of mammography, breast MRI, breast ultrasound, and other technologies for the detection of clinically occult breast cancer. $J$ Am Coll Radiol. 2010;7(1):18-27.

6. Houssami N, Abraham LA, Miglioretti DL, Sickles EA, Kerlikowske K, Buist DS, Geller BM, Muss HB, Irwig L. Accuracy and outcomes of screening mammography in women with a personal history of early-stage breast cancer. JAMA. 2011;305:790-9.

7. Buist DS, Abraham LA, Barlow WE, et al. Diagnosis of second breast cancer events after initial diagnosis of early stage breast cancer. Breast Cancer Res Treat. 2010;124(3):863-873.

8. Arasu VA, Joe BN, Lvoff NM et al. Benefit of Semiannual Ipsilateral Mammographic Surveillance Following Breast Conservation Therapy Radiology. 2012;264(2):371-377.

9. Keating NL, Landrum MB, Guadagnoli E, Winer EP, Ayanian JZ. Factors Related to Underuse of Surveillance Mammography Among Breast Cancer Survivors. J Clin Oncol. 2006;24(1):85-94.

10. Enewold L, McGlynn KA, Zahm SH, et al. Surveillance mammography among female DOD beneficiairies: as study by race and ethnicity. Cancer. 2013; 119(19): 3531-3538.

11. Onega T, Weiss $\mathbf{J}$, diFlorio $\mathbf{R}$, Mackenzie T, Goodrich $\mathbf{M}$, Poplack S. Evaluating Surveillance Breast Imaging and Biopsy in Older Breast Cancer Survivors. Int J Breast Cancer. 2012; 2012:347646.

12. Wirtz HS, Boudreau DM, Gralow JR et al. Factors associated with longterm adherence to annual surveillance mammography among breast cancer survivors. Breast Cancer Res Treat. 2014;143(3):541-50.

13. Ruddy KJ, Sangaralingham L, Freedman RA, et al. Adherence to Guidelines for Breast Surveillance in Breast Cancer Survivors. J Nat Compr Canc Netw. 2018;16(5):526-534.

14. Nekhlyudov L, Habel LA, Achacoso NS, et al. Adherence to Long-Term Surveillance Mammography Among Women with Ductal Carcinoma In Situ Treated with Breast-Conserving Surgery. J Clin Oncol. 2009;27(19):3211-3216.

15. Nekhlyudov L, Habel LA, Achacoso N, et al. Ten-Year Risk of Diagnostic Mammograms and Invasive Breast Procedures After Breast-Conserving Surgery for DCIS. J Natl Cancer Inst. 2012;104:614-621.

16. Wernli KJ, DeMartini WB, Ichikawa $\mathbf{L}$, et al. Patterns of Breast Magnetic Resonance Imaging Use in Community Practice. JAMA Intern Med. 2014;174(1):125-132.

17. Stout NK, Nekhlyudov $\mathbf{L}, \mathbf{L i} \mathbf{L}$, et al. Rapid Rise of Breast Magnetic Resonance Imaging Use: Trends from 2000-2011. JAMA Intern Med. 2014; 174(1):114-121.

18. Brandzel S, Rosenberg DE, Johnson D, et al. Women's experiences and preferences regarding breast imaging after completing breast cancer treatment. Patient Prefer Adherence. 2017;11:199-204.

19. Wernli KJ, Brandzel SD, Buist DSM, Bush M, DeMartini W, Ichikawa L, Haas C, Henderson LM, Johnson D, Kerlikowske K, McColgin D, Miglioretti CL, Nekhlyudov L, Onega T, Rosenberg DE. Comparative effectiveness of surveillance imaging modalities in breast cancer survivors. In press, Final research report to Patient Centered Outcomes Research Institute. 2018.

20. Breast Cancer Surveillance Consortium. 2016 [updated June 2016; Accessed 11/16/17]; Available from: http://www.bcsc-research.org/. Accessed 05/07/2019.

21. Ballard-Barbash R, Taplin SH, Yankaskas BC, Ernster VL, Rosenberg RD, Carney PA, Barlow WE, Geller BM, Kerlikowske K, Edwards BK, Lynch CF, Urban N, Chrvala CA, Key CR, Poplack SP, Worden JK, Kessler LG. Breast Cancer Surveillance Consortium: a national mammography screening and outcomes database. AJR Am J Roentgenol. 1997; 169:1001-8

22. Edge SB, Byrd DR, Compton CC, Fritz AG, Greene FL, Trotti A editors. AJCC cancer staging manual. 7th ed. New York: Springer-Verlag; 2009.

23. Gail MH, Brinton LA, Byar DP, Corle DK, Green SB, Shairer C, Mulvihill JJ: Projecting individualized probabilities of developing breast cancer for white females who are being examined annually. J Natl Cancer Inst. 1989;81(24):1879-86.

24. Costantino JP, Gail MH, Pee D, Anderson S, Redmond CK, Benichou $\mathbf{J}$, Wieand HS: Validation studies for models projecting the risk of invasive and total breast cancer incidence. J Natl Cancer Inst. 1999;91(18):1541-8.

25. Gail MH, Costantino JP, Bryant J, Croyle R, Freedman L, Helzlsouer $\mathbf{K}$, Vogel V: Weighing the risks and benefits of tamoxifen treatment for preventing breast cancer. J Natl Cancer Inst. 1999;91(21):1829-46.

26. Rockhill B, Spiegelman D, Byrne C, Hunter DJ, Colditz GA: Validation of the Gail et al. model of breast cancer risk prediction and implications for chemoprevention. J Natl Cancer Inst. 2001;93(5):358-66. 
27. Gail MH, Costantino JP, Pee D, Bondy M, Newman L, Selvan M, Anderson GL, Malone KE, Marchbanks PA, McCaskill-Stevens W, Norman SA, Simon MS, Spirtas R, Ursin G, and Bernstein L. Projecting Individualized Absolute Invasive Breast Cancer Risk in African American Women. J Natl Cancer Inst. 2007;99(23):1782-1792.

28. Matsuno RK, Costantino JP, Ziegler RG, Anderson GL, Li H, Pee D, Gail MH. Projecting Individualized Absolute Invasive Breast Cancer Risk in Asian and Pacific Island American Women. J Natl Cancer Inst. 2011;103(12):951-61.

29. Tice JA, Cummings SR, Smith-Bindman R, et al. Using Clinical Factors and Mammographic Breast Density to Estimate Breast Cancer Risk: Development and Validation of a New Predictive Model. Ann Intern Med. 2008;148(5):337-47.

30. NCI-funded Breast Cancer Surveillance Consortium (P01 CA154292 and HHSN261201100031C). Downloaded 05/07/2019 from the Breast Cancer Surveillance Consortium Web site - https://tools.bcsc-scc.org/ BC5yearRisk. Accessed 05/07/2019.

31. Patel BK, Lee CS, Kosiorek HE et al. Variability of Postsurgical Imaging Surveillance of Breast Cancer Patients: A Nationwide Survey Study. AJR 2018;210:222-227.
32. Center for Medicare and Medicaid Services (CMS) National Coverage Determination for Mammograms 220.4. https://www.cms.gov/medicare-coverage-database /details/ncd-details.aspx?CALId $=181 \&$ CalName=Prothrombin+Time+(Addition+of+ICD-9-CM+289.81\%2C+Primary+Hypercoagulable+State+as+a+Covered+Indication)\&ExpandComment$\mathrm{s}=\mathrm{y} \&$ CommentPeriod=0\&NCDId=186\&ncdver $=1 \&$ CoverageSelection=National\&bc=gAAAABAAQEAAAA\%3D\%3D\&. Accessed 05/07/2019.

33. American College of Radiology (ACR) Practice Parameter of Screening and Diagnostic Mammography. https://www.acr.org/-/media/ACR/Files/ Practice-Parameters/Dig-Mamo.pdf. Accessed 05/07/2019.

34. Lehman CD, Arao RF, Sprague BL, et al. National Performance Benchmarks for Modern Screening Digital Mammography: Update from the Breast Cancer Surveillance Consortium. Radiology. 2017;283(1):49-58.

35. Sprague BL, Arao RF, Miglioretti DL, et al. National Performance Benchmarks for Modern Diagnostic Digital Mammography: Update from the Breast Cancer Surveillance Consortium. Radiology. 2017;283(1):5969.

Publisher's Note Springer Nature remains neutral with regard to jurisdictional claims in published maps and institutional affiliations. 